\title{
Intramuscular haloperidol-promethazine sedates violent or agitated patients more quickly than intramuscular lorazepam
}

Alexander J, Tharyan P, Adams C, et al. Rapid tranquillisation of violent or agitated patients in a psychiatric emergency setting. Pragmatic randomised trial of intramuscular lorazepam v. haloperidol plus promethazine. Br J Psychiatry 2004; 185:63-9.

\section{$Q$ Is lorazepam an effective alternative to haloperidol-promethazine for rapid tranquilisation of violent or agitated psychiatric patients?}

\section{METHODS}

$\square-$

Design: Randomised controlled trial.

2

Allocation: Not reported.

Blinding: Assessors for primary outcome were blind to treatmen allocation. Other assessors were unblinded.

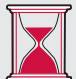

Follow up period: Four hours.

Setting: Psychiatric emergency services at a medical college in Vellore in Tamil Nadu, India in 2002.

Patients: 200 people with disruptive behaviour requiring intramuscular sedation at presentation to emergency psychiatric services. People at risk of complication from either treatment were excluded. Participants had a range of psychiatric diagnoses (psychoses, affective disorders, and substance misuse).

$\mathbf{R}_{\mathbf{X}}$

Intervention: Intramuscular haloperidol (10 mg) plus promethazine ( 25 or $50 \mathrm{mg}$, at physician's discretion) or intramuscular lorazepam (4 mg).

Outcomes: Proportion of participants tranquil or asleep at 4 hours; time to achieve a tranquil or sleep state.

Patient follow up: $100 \%$ for lorazepam group and $99 \%$ for haloperidol-promethazine at 4 hours.

\section{MAIN RESULTS}

There was no significant difference between treatment groups in proportion of participants tranquil or asleep at 4 hours $(96 / 100$ in each group; RR 1.0, 95\% CI 0.94 to 1.06). However, haloperidolpromethazine significantly reduced time to tranquilisation and sleep

For correspondence: Dr Jacob Alexander, Department of Psychiatry Christian Medical College, Vellore 632002, Tamil Nadu, India; dralexander_in@yahoo.com

Sources of funding: Fluid Research Fund, Christian Medical College and Cochrane Schizophrenia general fund. (mean time to tranquilisation: 47.8 minutes with lorazepam $v$ 29.7 minutes with haloperidol-promethazine; $p=0.0001$; mean time to sleep: 80.6 minutes with lorazepam $v 37.4$ minutes with haloperidol-promethazine; $\mathrm{p}<0.0001$ ).

\section{CONCLUSIONS}

Intramuscular haloperidol and promethazine sedates violent or agitated patients more quickly than intramuscular lorazepam.

\section{Commentary}

$\mathrm{n}$ an era when the majority of RCTs conducted in mental health are funded by the pharmaceutical industry, include only highly selected patients, have complex and multiple outcome measures, and generally have poor completion rates, it is a breath of fresh air to read the study by Alexander et al. This is a pragmatic study in that it included all consecutive patients who were deemed to require rapid tranquilisation by their treating physician, irrespective of diagnosis, and they achieved a remarkable $99.5 \%$ follow up rate. The findings from the study are very convincing. This Indian study needs to be considered alongside a similar study conducted in Brazil that compared haloperidol plus promethazine with midazolam; ${ }^{1}$ interestingly in this case the benzodiazepine worked fastest.

The choice of medication in these two studies was heavily influenced by current local practice. In many parts of the world intramuscular olanzapine has recently become available and hence rather different medication comparisons are needed than the ones investigated. In the UK at least it does not appear that the results will have a direct impact on clinical practice. The National Institute of Clinical Excellence is currently drawing up guidelines for the management of disturbed behaviour. ${ }^{2}$ They feel that there are insufficient safety data to recommend intramuscular haloperidol plus promethazine. Given this and the fact that promethazine is rarely, if ever, used in the UK, it is hard to see this combination catching on. It is perhaps more likely that the findings of these studies will impact on clinical practice in areas where intramuscular olanzapine is either not available or too costly. Nevertheless, the main conclusion that can be drawn from this study is that good quality pragmatic trials are possible in psychiatry. Many more are needed.

Dr R Hamish McAllister-Williams PhD, MD, MRCPsych University of Newcastle upon Tyne, UK

1 TREC Collaborative Group. Rapid tranquillisation for agitated patients in emergency psychiatric rooms: a randomised trial of midazolam versus haloperidol plus promethazine. BMJ 2003;327:708-13.

2 National Institute for Clinical Excellence. Disturbed behaviour clinical guideline: second consultation - NICE guideline. Available from http:// www.nice.org.uk/page.aspx?o=211596 (accessed November 2004). 